\title{
Are the Associations between Life-style Related Factors and Plasma Total Homocysteine Concentration Different According to Polymorphism of 5,10-Methylenetetrahydrofolate Reductase Gene (C677T MTHFR)?
}

\section{- A Cross-sectional Study in a Japanese Rural Population -}

\author{
Htay Lwin ${ }^{1}$, Tetsuji Yokoyama ${ }^{1}$, Chigusa Date ${ }^{2}$, Nobuo Yoshiike $^{3}$, Yoshihiro Kokubo ${ }^{4}$ and Heizo Tanaka ${ }^{5}$
}

Mild hyperhomocysteinemia is one of the known strong risk factors for atherosclerotic diseases, and therefore it is important to clarify factors that could determine plasma total homocysteine (tHcy) level. A cross-sectional study with a random sample of 455 Japanese rural residents aged 40-69 years was conducted in 2000 to investigate the associations of plasma thcy concentration with 5,10-methylenetetrahydrofolate reductase (MTHFR) gene and selected life-style related factors. The frequency of the mutant allele, Valine $M$ allele, was 0.40 and the prevalence of $\mathrm{W}$ genotype was $14.3 \%$. Plasma tHcy concentration in $\mathrm{W}$ was significantly higher than those in two other genotypes. There were significant inverse associations of plasma tHcy with serum folate and serum vitamin $B_{12}(P<0.001$ for trend, respectively); both being stronger in $W$ than in other genotypes. The number of cigarettes smoked per day was positively associated with plasma tHcy concentration. A multivariate regression analysis revealed that serum folate, serum vitamin $\mathrm{B}_{12}$, and MTHFR genotype were independently associated with plasma tHcy. The inter-individual variance of plasma tHcy was more explained by serum folate and vitamin $B_{12}$ than by MTHFR genotype. Higher intakes of folate, vitamin $\mathrm{B}_{12}$, and non-smoking may be important to prevent mild hyperhomocysteinemia and the eventual atherosclerotic diseases in this Japanese rural population. J Epidemiol, $2002 ; 12: 126-135$

homocysteine, MTHFR, serum folate and vitamin $\mathrm{B}_{12}$, smoking, Japanese

\section{INTRODUCTION}

Epidemiological evidence indicates that higher plasma concentration of total homocysteine (tHcy), a thio containing amino acid metabolized by either remethylation to metionine or transsulfuration to cysteine, is a risk factor for atherosclerotic diseases such as coronary, cerebral, and peripheral arterial diseases ${ }^{1-3)}$. To improve programs for the primary prevention of these atherosclerotic diseases, it is important to clarify factors, whether genetic or environmental, that could determine the levels of plasma tHcy. A common genetic factor, 5,10Methylenetetrahydrofolate reductase (MTHFR) gene, and dietary factors such as folate, vitamin $B_{12}$, and vitamin $B_{6}$ have been suggested previously ${ }^{1-5}$. Although severe hyperhomocysteinemia is rare, mild hyperhomocysteinemia occurs in approximately $5 \%$ of general population due to these factors $1,2,5$ ) and may be prevented by life-style modification.

In the present cross-sectional study conducted in a Japanese rural population, we analyzed the associations of plasma tHcy concentration with polymorphism of C677T MTHFR, serum concentrations of folate and vitamins $B_{12}$ and $B_{6}$, daily physical activity, smoking, and alcohol drinking to examine the effects of these genetic and environmental factors on the plasma tHcy concentration. Furthermore, we analyzed associations between plasma tHcy concentrations and the environmental factors in

Received November 16, 2001; accepted January 8, 2002.

${ }^{1}$ Department of Epidemiology, Medical Research Institute, Tokyo Medical and Dental University, 2-3-10, Kanda-surugadai, Chiyoda-ku, Tokyo 101-0062, Japan.

2 Department of Public Health, Osaka City University Medical School, Osaka, Japan.

${ }^{3}$ Division of Health and Nutrition Monitoring, National Institute of Health and Nutrition, Tokyo, Japan.

+ Department of Preventive Cardiology, National Cardiovascular Center, Osaka, Japan.

${ }^{5}$ National Institute of Health and Nutrition, Tokyo, Japan.

Address for correspondence: Htay Lwin, MBBS, Department of Epidemiology, Medical Research Institute, Tokyo Medical and Dental University, 2-3-10, Kanda-surugadai, Chiyoda-ku, Tokyo 101-0062, Japan. 
each of MTHFR genotypes separately because the metabolic pathways of homocysteine involve MTHFR and many cofactors (e.g. folate, vitamin $\mathrm{B}_{12}$, and vitamin $\mathrm{B}_{6}$ ) and, therefore, the strength of association between plasma tHcy concentration and environmental factors might be affected by the MTHFR genotype. Such knowledge about so-called the gene-environment interactions would be helpful to develop an optimal program of life-style modification to control mild hyperhomocysteinemia for individuals with different MTHFR genotypes.

\section{MATERIALS AND METHODS}

\section{Study subjects}

The participants were randomly selected from all residents aged 40-69 years in Shiso, a rural county located in the northwestern part of Hyogo Prefecture, Japan, in 2000. The present cross-sectional study was carried out as a part of a longitudinal study to continuously monitor the changes in life-styles and risk factors of cardiovascular diseases in this area during the last decade ${ }^{6)}$. The sample size was determined to detect a statistically significant difference of plasma tHcy levels according to MTHFR genotypes on the basis of some previous studies ${ }^{1,7-11)}$. All participants were assembled in local community halls, where 213 men and 242 women completed the following examinations.

The present study was approved by the ethics review committee of Medical Research Institute, Tokyo Medical and Dental University. All the subjects were taken for written informed consent.

\section{Assessment of life-style factors}

Under a supervision of nurses or dietitians specifically trained for this study, each of the participants completed standardized questionnaires that included items about physical activity, smoking and alcohol drinking habits, and others. Smoking habit was classified into three groups as non-smokers (including ex-smokers), 1-19, and 20+ cigarettes/day. Daily alcohol drinking was also classified into three groups as $0-2.0$, 2.1-4.0, and $4.1+$ drinks/day, where one drink is approximately 12 grams of ethanol. Smoking and alcohol drinking were analyzed only in men because the prevalence of these was markedly higher in men than that in women. To evaluate the usual degree of physical activity, we used the intensity of physical activity as determined by a metabolic equivalents (METs) score, which was calculated as follows. Aside from sleeping time, the frequency and average duration of various types of labor and other activities on the job, including household activities, for every 2 months within the last 12 months were queried ${ }^{6}$. One MET is as the resting metabolic rate, or approximately equivalent to $1 \mathrm{kcal} / \mathrm{kg}$ body weight per hour ${ }^{12)}$. In this report, we used the 'active intensity index' that was defined as the average METs during the time except sleeping. Body fat percentage was measured by the fitness analyzer, BFT-2000
(Kett Electric Laboratory, Japan), which was based on the near-infrared interactance technology. We measured serum concentrations of folate, vitamin $\mathrm{B}_{12}$, and vitamin $\mathrm{B}_{6}$ (pyridoxal 5'-phoshate), because their blood concentrations were known as biochemical indicators of dietary intake ${ }^{13}$.

\section{Blood collection and measurements}

Venous blood was drawn into EDTA-tube and serum tube after an overnight (12-h) fast. Then, the sample was immediately prepared at $4{ }^{\circ} \mathrm{C}$, and frozen and kept at $-20^{\circ} \mathrm{C}$. The level of plasma tHcy was determined as total by high-performance liquid chromatography (HPLC) with fluorescence detection ${ }^{14)}$. Serum folate and serum vitamin $B_{12}$ were measured by using Chemiluminescent analyzer ACS-180 (Chiron Corp, Califonia). Serum vitamin B6 (pyridoxal-5'-phosphate) levels were measured by using a HPLC equipped with a fluorescence detector.

\section{Genetic analysis}

DNA was extracted from white blood cells with Puregene (Gentra Systems, Inc). Genotyping for MTHFR polymorphism was performed by polymerase chain reaction (PCR), with using the primers. The sequences of primers used in this study were the sense primer (5'-CAA AGG CCA CCC CGA AGC-3') and anti-sense primer ( $5^{\prime}$-AGG ACG GTG CGG TGA GAG TG-3'). All PCRs to detect the MTHFR mutation were performed (amplified for 35 cycles consisting of denaturing at $94^{\circ} \mathrm{C}$ for $30 \mathrm{sec}$, annealing at $60^{\circ} \mathrm{C}$ for $60 \mathrm{sec}$ and extension at $72^{\circ} \mathrm{C}$ for $60 \mathrm{sec}$, followed by a final extension step at $72^{\circ} \mathrm{C}$ for 10 min). Genotype was determined by digestion with HinfI (Takara Co. Ltd), followed by $10 \%$ polyacrylamide gel electrophoresis and ethidium bromide $(1 \mu \mathrm{g} / \mathrm{ml})$ staining $7,8,15,16,17)$.

\section{Statistical analyses}

Plasma tHcy, serum folate, serum vitamin $B_{12}$, serum vita$\min B_{6}$, and active intensity index were expressed as means \pm SDs or logarithmic means \pm SDs . Since the frequency distribution of plasma tHcy, the dependent variable in the present study, was skewed to the right side, the values were logarithmically transformed to follow an approximate normal distribution. Frequencies of alleles and genotypes of MTHFR were shown in percentage. Deviation of the genotype distribution from Hardy-Weinberg equilibrium was tested by $\chi^{2}$ analysis.

As for life-style factors, smoking and drinking were respectively classified into three groups as mentioned above. The values of physical activity, serum folate, serum vitamin $B_{12}$, and serum vitamin $\mathrm{B}_{6}$ were logarithmically transformed for the same reason as plasma tHcy.

The associations of plasma tHcy with MTHFR genotype or selected life-style factors were examined by analysis of variance (ANOVA) followed by Tukey's multiple comparison tests. Age- and sex-adjusted least square mean (LSM) of plasma tHcy in each of the combination between MTHFR genotypes and categories of life-style factors (categorized by tertiles 
for continuous variables) was calculated by analysis of covariance (ANCOVA). The strength of association between plasma thcy and life-style factors was expressed as a standardized regression coefficient (std B) for each of the MTHFR genotypes, and difference of the std Bs among the genotypes was tested by including the interaction term of life-style factor $X$ genotype. Finally, the multiple regression analysis was performed to examine the independent contribution of MTHFR genotype and life-style factors to plasma tHcy, and the independent variables were sex, age, MTHFR genotypes, serum folate, senum vitamin $B_{12}$ and interaction terms of serum folate $\times$ MTHFR genotypes which were significantly associated with plasma thcy in the sex- and age-adjusted univariate analysis. All of the analyses were done with SAS statistical package (version 6.12, SAS Institute).

\section{RESULTS}

\section{Characteristics of the study subjects}

Table 1 shows the basic characteristics of the subjects participating in this study. Mean age of men and women was $49.0 \pm$
8.2 years and $49.7 \pm 8.2$ years, respectively. The mean level of plasma tHcy was significantly higher in men than in women. The frequency of VV genotype in men ( $16 \%$ ) was slightly higher than that in women (12.9\%) although not statistically significant. Serum folate was significantly higher in women than in men. The prevalence of male smokers $(20+$ cigarettes/day) was $45.4 \%$ and that of male drinkers (4.1+ drinks/day) was $28.3 \%$.

\section{Plasma tHcy and C677T MTHFR genotypes}

The frequency of mutant allele ( $\mathrm{V}$ allele) of MTHFR was 0.40 ; the frequencies of three genotypes were AA $34.3 \%$, AV $51.4 \%$, and VV $14.3 \%$. The distribution of the genotypes did not differ from the values expected for the Hardy-Weinberg equilibrium ( $\chi^{2}=2.09$, df $\left.=1, P=0.48\right)$. Age- and sex-adjusted LSM of plasma tHcy level in MTHFR mutant genotype (VV) was significantly higher than those in two other genotypes (Table 2).

\section{Plasma tHcy and life-style factors}

Table 3 shows LSM of plasma tHcy (log and non log-trans-

Table 1. Basic characteristics of the subjects in Shiso, a Japanese rural county, in 2000.

\begin{tabular}{|c|c|c|}
\hline & Men $(n=213)$ & Women $(n=242)$ \\
\hline Age, yr & $49.0 \pm 8.2$ & $49.7 \pm 8.2$ \\
\hline \multirow[t]{2}{*}{ Plasma tHcy, $\mu \mathrm{mol} / 1$} & $13.3 \pm 3.1$ & $9.9 \pm 2.5^{*}$ \\
\hline & $(2.56 \pm 0.21) \dagger$ & $(2.27 \pm 0.21) \dagger$ \\
\hline \multicolumn{3}{|l|}{ MTHFR genotype $\ddagger$} \\
\hline $\mathrm{AA}$ & $31.9 \%$ & $36.3 \%$ \\
\hline AV & $52.1 \%$ & $50.8 \%$ \\
\hline VV & $16.0 \%$ & $12.9 \%$ \\
\hline \multirow[t]{2}{*}{ Serum folate, $\mathrm{ng} / \mathrm{ml}$} & $7.8 \pm 3.5$ & $10.3 \pm 3.8^{*}$ \\
\hline & $(1.96 \pm 0.41) \dagger$ & $(2.26 \pm 0.35) \dagger$ \\
\hline \multirow[t]{2}{*}{ Serum vitamin $B_{12,} \mathrm{ng} / \mathrm{ml}$} & $640.8 \pm 296.6$ & $726.5 \pm 460.1$ \\
\hline & $(6.39 \pm 0.36) \dagger$ & $(6.49 \pm 0.41) \dagger$ \\
\hline \multirow[t]{2}{*}{ Serum vitamin $B 6, \mathrm{ng} / \mathrm{ml}$} & $24.3 \pm 87.4$ & $16.8 \pm 21.0$ \\
\hline & $(2.60 \pm 0.77) \dagger$ & $(2.48 \pm 0.73) \dagger$ \\
\hline \multicolumn{3}{|l|}{ Smoking (cigarettes/day) } \\
\hline 0 & $43.9 \%$ & $97.9 \%$ \\
\hline $1-19$ & $10.7 \%$ & $1.7 \%$ \\
\hline $20+$ & $45.4 \%$ & $0.4 \%$ \\
\hline \multicolumn{3}{|l|}{ Alcohol drinking (drinks/day)II } \\
\hline $0-2.0$ & $46.2 \%$ & $94.2 \%$ \\
\hline $2.1-4.0$ & $25.5 \%$ & $3.7 \%$ \\
\hline $4.1+$ & $28.3 \%$ & $2.1 \%$ \\
\hline $\mathrm{BMI}\left(\mathrm{kg} / \mathrm{m}^{2}\right)$ & $23.2 \pm 2.9$ & $22.7 \pm 3.1$ \\
\hline \multirow[t]{2}{*}{ Active intensity index, METs } & $2.05 \pm 0.43$ & $2.01 \pm 0.32$ \\
\hline & $(0.70 \pm 0.20) \dagger$ & $(0.69 \pm 0.15) \dagger$ \\
\hline
\end{tabular}

Values are means \pm SDs or percentages.

* $\mathbf{P}<0.05$ for comparison between sexes.

$\uparrow$ Means \pm SDs of log-transformed values

$\ddagger \chi^{2}=2.09, \mathrm{df}=1, \mathrm{P}=0.48$ for comparison with Hardy-Weinberg equilibrium among all subjects.

II One drink is approximately 12 grams of ethanol. 
Table 2. Plasma total homocysteine level according to MTHFR genotype.

\begin{tabular}{lllll}
\hline & \multicolumn{3}{c}{ MTHFR genotype } & \multirow{2}{*}{$\mathrm{P}^{*}$} \\
\cline { 2 - 4 } & $\mathrm{AA}(\mathrm{n}=156)$ & $\mathrm{AV}(\mathrm{n}=234)$ & $\mathrm{VV}(\mathrm{n}=65)$ & \\
\hline Plasma tHcy, $\mu \mathrm{mol} / 1$ & $11.1 \pm 0.21 \dagger$ & $11.3 \pm 0.18 \ddagger$ & $13.3 \pm 0.34$ & 0.0001 \\
\hline Values are age- and sex-adjusted least square means \pm SEs. & & \\
$* \mathrm{P}$ for homogeneity among the genotype groups. & & \\
$\dagger \mathrm{P}<0.05$ for AA vs VV. \\
$\ddagger \mathrm{P}<0.05$ for AV vs VV by Tukey's multiple comparison.
\end{tabular}

Table 3. Plasma total homocysteine and selected life-style factors.

\begin{tabular}{|c|c|c|}
\hline & Plasma tHcy $(\log \mu \mathrm{mol} / \mathrm{l})^{*}$ & Plasma tHcy $(\mu \mathrm{mol} / \mathrm{l}) \neq$ \\
\hline \multicolumn{3}{|c|}{ Serum folate $(\log \mathrm{ng} / \mathrm{ml}) \dagger$} \\
\hline$\leq 1.96$ & $2.48 \pm 0.02$ & $12.5 \pm 0.2$ \\
\hline$>1.96$ and $\leq 2.28$ & $2.42 \pm 0.02$ & $11.6 \pm 0.2$ \\
\hline$>2.28$ & $2.33 \pm 0.02$ & $10.5 \pm 0.2$ \\
\hline Std $B \pm S E$ & $-0.32 \pm 0.04$ & $-0.33 \pm 0.04$ \\
\hline$P$ for trend & 0.0001 & 0.0001 \\
\hline \multicolumn{3}{|c|}{ Serum Vitamin B $12(\log n g / m l) \dagger$} \\
\hline$\leq 6.27$ & $2.46 \pm 0.02$ & $12.1 \pm 0.2$ \\
\hline$>6.27$ and $\leq 6.55$ & $2.40 \pm 0.02$ & $11.5 \pm 0.2$ \\
\hline$>6.55$ & $2.36 \pm 0.02$ & $10.9 \pm 0.2$ \\
\hline Std $B \pm S E$ & $-0.16 \pm 0.04$ & $-0.17 \pm 0.04$ \\
\hline \multirow{2}{*}{\multicolumn{3}{|c|}{ Serum Vitamin B6 $(\log \mathrm{ng} / \mathrm{ml}) \dagger$}} \\
\hline & & \\
\hline$\leq 2.16$ & $2.41 \pm 0.02$ & $11.5 \pm 0.2$ \\
\hline$>2.16$ and $\leq 2.67$ & $2.40 \pm 0.02$ & $11.5 \pm 0.2$ \\
\hline$>2.67$ & $2.39 \pm 0.02$ & $11.3 \pm 0.2$ \\
\hline Std $B \pm S E$ & $-0.01 \pm 0.04$ & $-0.005 \pm 0.05$ \\
\hline P for trend & $0 . \overline{7} 7$ & 0.91 \\
\hline \multicolumn{3}{|c|}{ Smoking (cigarettes/day) (Men) } \\
\hline 0 & $2.53 \pm 0.02$ & $12.7 \pm 0.3$ \\
\hline $1 \sim 19$ & $2.54 \pm 0.04$ & $12.8 \pm 0.6$ \\
\hline$\geq 20$ & $2.60 \pm 0.02$ & $13.9 \pm 0.3$ \\
\hline$B \pm S E$ & $0.12 \pm 0.04 \mathrm{I}$ & $0.12 \pm 0.04 \pi$ \\
\hline$P$ for trend & 0.006 & 0.008 \\
\hline \multicolumn{3}{|c|}{ Alcohol drinking (drinks/day) (Men) } \\
\hline$\leq 2$ & $2.55 \pm 0.02$ & $13.2 \pm 0.3$ \\
\hline$>2$ and $\leq 4$ & $2.53 \pm 0.02$ & $12.8 \pm 0.4$ \\
\hline$>4$ & $2.60 \pm 0.03$ & $13.9 \pm 0.4$ \\
\hline$B \pm S E$ & $0.06 \pm 0.04 \Delta$ & $0.07 \pm 0.05 \Delta$ \\
\hline$P$ for trend & 0.17 & 0.12 \\
\hline \multicolumn{3}{|l|}{$B M I\left(\mathrm{~kg} / \mathrm{m}^{2}\right)$} \\
\hline$\leq 21.5^{\circ}$ & $2.38 \pm 0.02$ & $11.2 \pm 0.2$ \\
\hline$>21.5$ and $\leq 23.9$ & $2.41 \pm 0.02$ & $11.5 \pm 0.2$ \\
\hline$>23.9$ & $2.43 \pm 0.02$ & $11.7 \pm 0.2$ \\
\hline Std $\beta \pm S E$ & $0.04 \pm 0.04$ & $0.04 \pm 0.04$ \\
\hline$P$ for trend & 0.22 & 0.27 \\
\hline \multicolumn{3}{|c|}{ Active Intensity Index (METs) } \\
\hline$\leq 0.61$ & $2.42 \pm 0.02$ & $11.6 \pm 0.2$ \\
\hline$>0.61$ and $\leq 0.73$ & $2.40 \pm 0.02$ & $11.5 \pm 0.2$ \\
\hline$>0.73$ & $2.41 \pm 0.02$ & $11.5 \pm 0.2$ \\
\hline Std $B \pm S E$ & $-0.02 \pm 0.04$ & $-0.03 \pm 0.04$ \\
\hline$P$ for trend & 0.56 & 0.45 \\
\hline
\end{tabular}

* Values are age and sex adjusted Least Square Mean (LSM) \pm Standard Error (SE) of natural logarithm of plasma total homocysteine concentration $(\log \mu \mathrm{mol} / 1)$.

† Log-transformed values were used for the multivariate linear regression analyses and the classification was based on tertiles.

$\ddagger$ Values are age and sex adjusted least square mean (LSM) \pm standard error (SE) of plasma total homocysteine concentration $(\mu \mathrm{mol} / \mathrm{l})$.

Std $\beta \pm$ SE: Standardized regression coefficient \pm standard error by a multivariate linear regression model of plasma thcy concentration on each independent variable including sex and age as covariates.

II Caculated for 10 cigarettes.

$\Delta$ Caculated for 2 drinks. 
formed values) by tertile of selected life-style factors. Both serum folate and serum vitamin $B_{12}$ were inversely correlated with plasma tHcy; smoking was positively correlated to plasma tHcy. There were no statistically significant associations of plasma tHcy with serum vitamin $\mathrm{B}_{6}$, alcohol drinking, BMI, and physical activity.

\section{Associations between plasma $\mathrm{tHcy}$ and life-style factors accord- ing to MTHFR genotypes}

As shown in Table 4, an inverse association between plasma tHcy and serum folate was stronger in the order of $\mathrm{VV}$ (std $B=$ -0.42 ), $\mathrm{AV}$ (std $B=-0.33$ ), and $\mathrm{AA}$ (std $B=-0.17$ ) genotype, where the difference in the strength of association, expressed as std B, was statistically significant between $\mathrm{VV}$ and $\mathrm{AV}$ or AA genotype. Partial $R^{2}$ implied that the inter-individual variance of plasma tHcy was more explained by the level of senum folate (partial $R^{2}=0.075$ ) than by MTHFR genotypes (partial $\mathrm{R}^{2}=0.011$ ). Similarly, an inverse association between plasma thcy and serum vitamin $B_{12}$ was a little stronger in VV (std $B=-0.29$ ) than in $A V$ (std $B=-0.15$ ) or in $A A$ (std $B=-0.11$ ), but the difference of std $B$ was not statistically significant among three genotypes. No association was observed between plasma thcy and serum vitamin $B_{6}$ in any genotype.

Plasma thcy was higher in smokers, particularly in those with $20+$ cigarettes/day than in non-smokers, but this was statistically significant only in VV genotype. Alcohol drinking, $\mathrm{BMI}$, and physical activity were not related to plasma tHcy in any MTHFR genotype.

Multivariate analysis of association of plasma $\mathrm{tHcy}$ with MTHFR genotype and selected life-style factors

As shown in Table 5, MTHFR VV genotype, serum folate, and serum vitamin $B_{12}$ were independently associated with plasma tHcy. The interaction of serum folate $\times \mathrm{VV}$ genotype also indicated that serum folate was more strongly associated with plasma tHcy in VV genotype than in AA genotype even in the multivariate analysis. Partial $R^{2}$ of serum folate $(0.0652)$ and that of serum vitamin $B_{12}(0.0165)$ were larger than that of MTHFR genotype (0.0092). We added smoking habits as an independent variable to this model at the first step. but the association between smoking and tHcy was not significant $(P=0.18)$ and, therefore, we did not include smoking in the final analysis shown in Table 5.

\section{DISCUSSION}

Higher plasma tHcy is known as one of the strong risk factors for coronary heart disease and atherothrombotic stroke. A meta-analysis of 27 studies which investigated the relation between fasting tHcy levels and coronary artery disease (CAD) yielded an odds ratio of 1.6 for men and 1.8 for women for every $5 \mu \mathrm{mol} / \mathrm{l}$ increase in plasma thcy level, and also showed that a $5 \mu \mathrm{mol} / \mathrm{increase}$ in plasma tHcy elevated CAD risk by as much as an increase in total cholesterol of $20 \mathrm{mg} / \mathrm{dl}{ }^{18}$. A more recent review article indicated that the relative risk associated with a $5 \mu \mathrm{mol} / /$ increment in the tHcy level was 1.7 (95\% CI, 1.5-1.9) for coronary heart disease, 1.9 (95\% CI, 1.62.3) for cerebrovascular disease, and even higher for peripheral artery disease ${ }^{19)}$. Most of these epidemiological studies demonstrated that such risks were independent of other known risk factors. In our study, there were no significant associations between plasma tHcy and other major traditional cardiovascular risk factors such as SBP, DBP, TC, HDL-C, body fat percentage (data not shown), and BMI. This suggested that elevated plasma tHcy could be an independent risk factor for CAD in this Japanese rural population, although we did not examine the relationship between tHcy and risks of CAD. Therefore, it would be important to conduct more cross-sectional studies like ours to gain the knowledge that would allow a more advanced discussion to develop control measures against elevated plasma tHcy.

Inherited disorders (MTHFR thermolability), which are present in approximately $5 \%$ of a general population ${ }^{20)}$, can alter enzyme activity in the transsulfurration and remethylation pathways ${ }^{1,7,19,21,22)}$, and these may result in elevated tHcy levels. The C677T MTHFR gene was shown to be responsible for the thermolabile enzyme ${ }^{17,21,22,23)}$ and the mutation altered the enzyme activity in the transsulfurration and remethylation pathways $1,7,19,21,22)$. In our study, the C677T MTHFR genotype mutation, particularly homozygous, was significantly associated with the elevated plasma tHcy. This finding was almost consistent with previous Japanese studies conducted with a relatively small number of individuals ${ }^{17,2)}$ or CAD patients ${ }^{8}$. In addition, Frosst et al. ${ }^{17}$ reported that the VV genotype resulted in reducing the activity of MTHFR enzyme and raising the level of plasma tHcy in French Canadian subjects. Several Japanese studies 9, 10, 11) showed that MTHFR mutation was significantly associated with the risk of CAD although such an association was not observed in several studies conducted in the US and Australian populations ${ }^{24-26)}$.

A multivariate linear regression analysis revealed that there was a significant inverse association between plasma tHcy and serum folate levels in individuals with any MTHFR genotype. Interestingly, we found that this inverse association was significantly stronger in VV genotype than in AA genotype. This finding supported the hypothesis that folate might stabilize the MTHFR enzyme activity ${ }^{17}$; furthermore it may be consistent with the observation in which the oral supplementation of folic acid normalized hyperhomocysteinemia due to thermolabile MTHFR ${ }^{27,28)}$. Our results also supported that when folate concentration was high, this common genetic variant had little effect on tHcy levels ${ }^{7,24,29,30)}$. The present study demonstrated significant associations of MTHFR VV genotype with not only higher tHcy levels but also lower serum folate levels. This finding was consistent with the NHLBI Family Heart Study ${ }^{7}$ and other studies ${ }^{24,31}$. MTHFR catalyzes the synthesis of 5 - 
Table 4. The effects of combinations between MTHFR genotypes and selected life-style factors onto the plasma total homocysteine concentration.

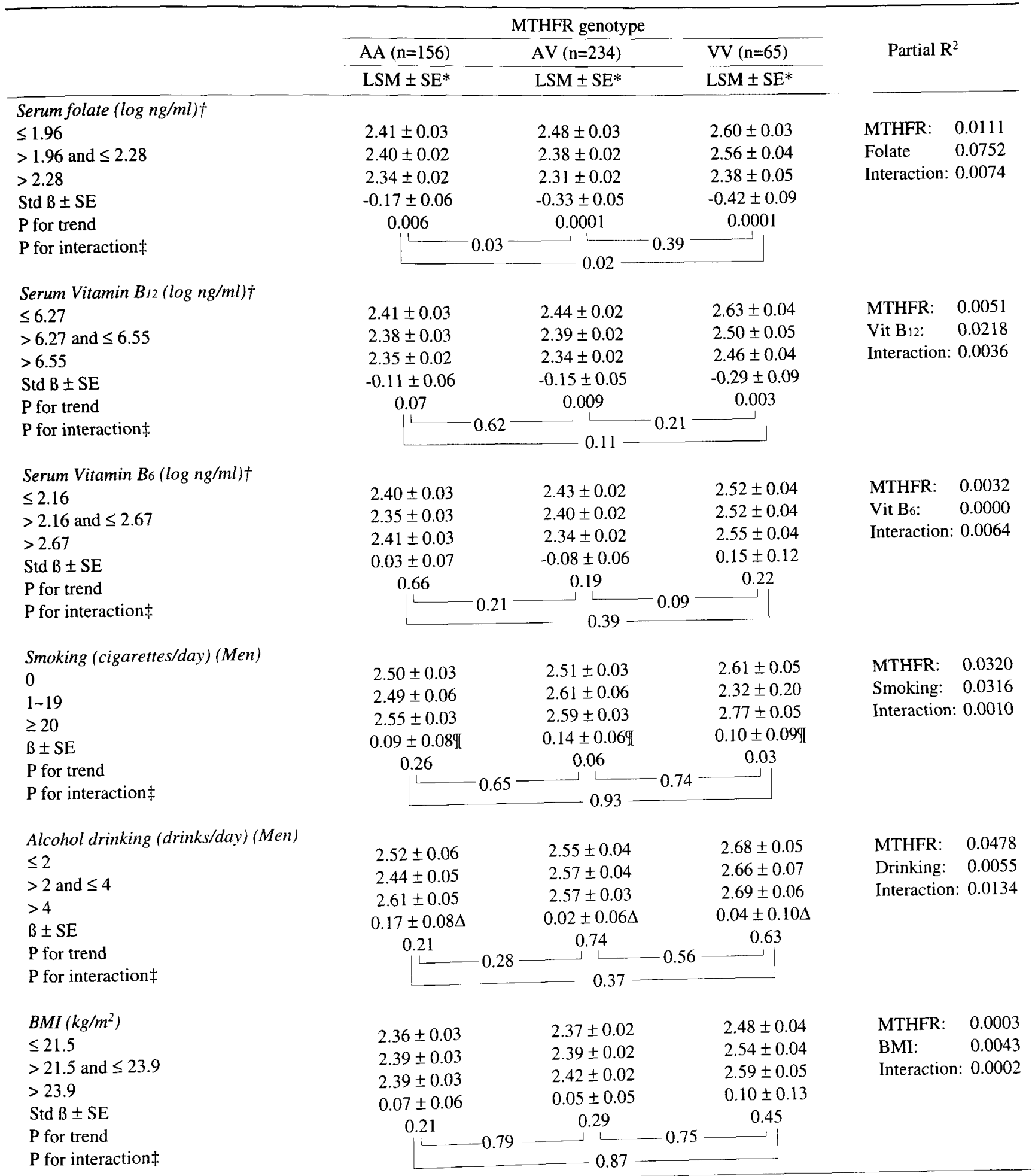

To be continued. 


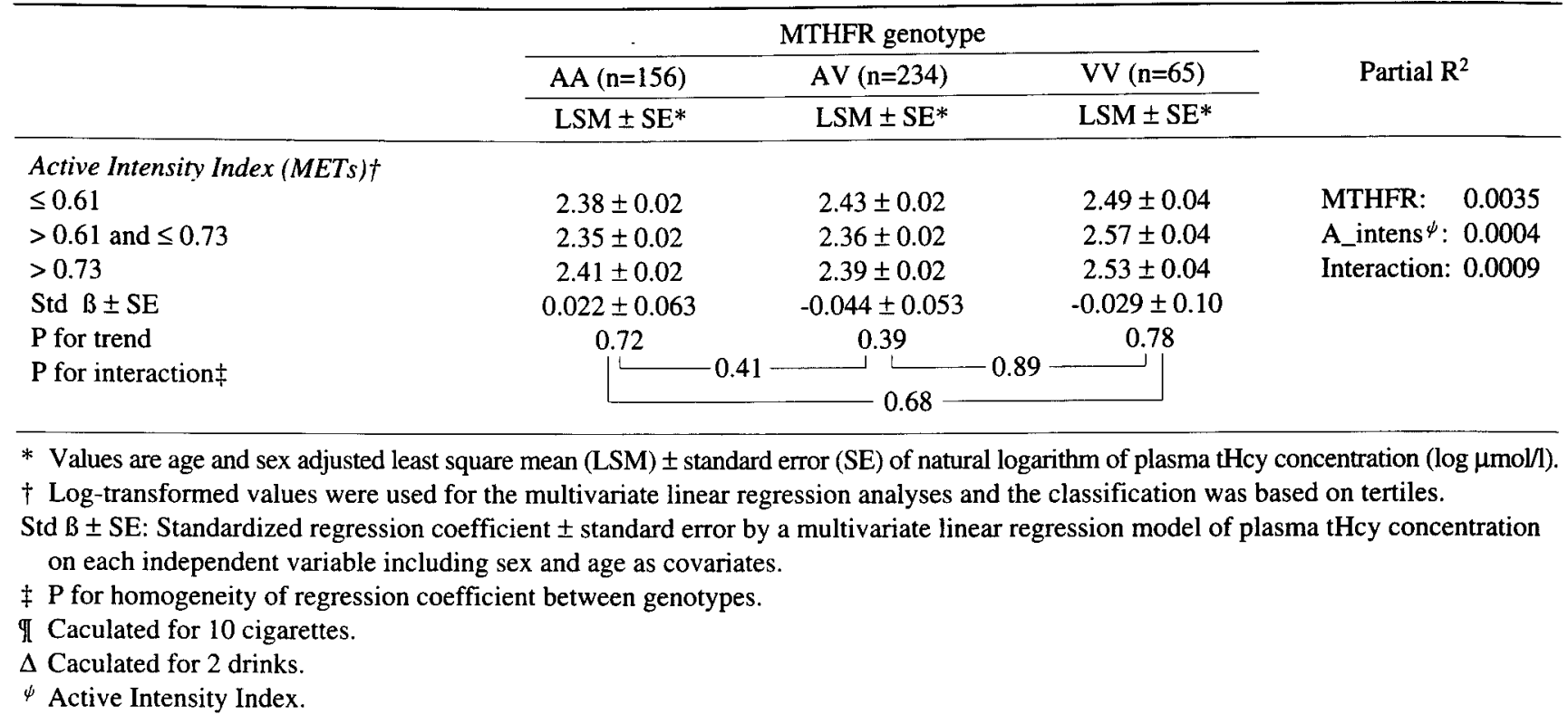

Table 5. Association of plasma tHcy with MTHFR genotypes and selected life-style factors in a multiple regression analysis.

\begin{tabular}{lclll}
\hline & Std $B \pm \mathrm{SE}$ & \multicolumn{1}{c}{$\mathrm{P}$} & \multicolumn{2}{c}{ Partial $\mathrm{R}^{2}$} \\
\hline Serum folate & $-0.19 \pm 0.09$ & 0.003 & MTHFR: & 0.0092 \\
MTHFR AV $\dagger$ & $-0.006 \pm 0.08$ & 0.94 & Folate: & 0.0652 \\
MTHFR VV $\dagger$ & $0.41 \pm 0.12$ & 0.0004 & Interaction: 0.0057 \\
Serum folate $\times \mathrm{AV} \dagger$ & $-0.14 \pm 0.08$ & $0.08 \ddagger$ & Vit B $12:$ & 0.0165 \\
Serum folate $\times \mathrm{VV} \dagger$ & $-0.24 \pm 0.12$ & $0.04 \ddagger$ & & \\
Serum Vitamin $\mathrm{B}_{12}$ & $-0.14 \pm 0.04$ & 0.0002 & & \\
\hline
\end{tabular}

Std $B \pm$ SE: Standardized regression coefficient \pm Standard Error by a multivariate linear regression model of plasma tHcy concentration on each independent variable after age and sex adjusted.

$\dagger$ Using AA as reference.

$\ddagger \mathrm{P}$ for homogeneity of regression coefficient between genotypes.

methyltetrahydrofolate, main circulatory form of folate and the methyl donor in the remethylation of homocysteine to methionine ${ }^{24,32,33)}$. The VV genotype is associated with a thermolabile enzyme with $50 \%$ of normal activity ${ }^{17}$. Our results suggest that the remethylation pathway becomes detectably inadequate, resulting in excess homocysteine, in the absence of sufficient substrate and the presence of suboptimal enzymatic activity.

Several studies demonstrated an inverse relationship between vitamin $B_{12}$ status and plasma homocysteine levels ${ }^{34-38)}$ although the strength of the correlation was not as strong as that observed between folate status and homocysteine levels. Our result also showed that plasma tHcy was significantly and inversely associated with serum vitamin $B_{12}$ concentration. Vitamin $B_{12}$ in the form of methycobalamine is required as cofactor and folate in the form of 5-methyltetrahydrofolate is a co-substrate for the vitamin $\mathrm{B}_{12}$-dependent remethylation of homocysteine to methionine ${ }^{23,39)}$. Our result suggested that vitamin $\mathrm{B}_{12}$ was an essential factor as well as folate for the metabolism of homocysteine.

We did not find any relationship between serum vitamin B6 and plasma thcy levels. Some previous studies reported a nonsignificant relationship ${ }^{40-44)}$ like ours whereas others reported a significant inverse relationship ${ }^{36,45,46)}$ between homocysteine levels and vitamin $\mathrm{B}_{6}$ status. Thus, currently the relationship between vitamin $\mathrm{B}_{6}$ and plasma homocysteine remained unclear. Further studies would be needed using larger samples controlling for potential confounders.

Smoking was significantly and positively associated with the 
plasma tHcy level. This result was very similar to other studies ${ }^{10,31,47,48}$. Plasma tHcy level was positively associated with status of smoking in any genotype being significant only in VV genotype. In the multivariate analysis after adjusted for serum folate and vitamin $B_{12}$, the relationship between smoking and plasma tHcy became non-significant. In addition, we also found that smoking was inversely associated with serum folate $(r=-0.32, P=0.0001)$ and vitamin $B_{12}(r=-0.20, P=0.0039)$ after adjusted for age and sex. Thus, it is plausible that cigarette smoking have caused a lower folate and vitamin $\mathrm{B}_{12}$ status and an eventual elevation of homocysteine concentration ${ }^{49}$. Regardless of the individual's MTHFR genotype, we should educate people to quit smoking for the prevention of hyperhomocysteinemia as well as other known many health problems.

Alcohol drinking was not associated with the level of plasma thcy. Some studies observed that there was a modest association between alcohol intake and fasting tHcy, and significant positive associations were seen between tHcy and consumption of hard liquor and red wine, but not of beer ${ }^{50,51)}$. In our study, the majority of alcohol beverages consumed was beer. Therefore, the lack of association between alcohol drinking and plasma tHcy might be due to the type of alcohol beverages consumed in this population.

BMI was not associated with plasma tHcy and MTHFR genotype. This result supported to Gudnason et al ${ }^{22}$, although Wilcken et al ${ }^{25}$ observed that BMI was significantly associated with MTHFR mutation. BMI may be related to intake of total energy and hence other nutrients such as folate, vitamin $B_{12}$, and $B_{6}$. However, adjustment for BMI virtually unchanged the associations of folate, vitamin $B_{12}$, and $B_{6}$ with plasma

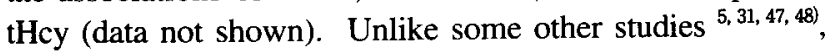
there was no association between plasma tHcy and daily physical activity in our study. We further need to study for elucidating other potential confounding factors to explain this result.

In the multivariate analysis, MTHFR mutant genotypes, serum folate, and serum vitamin $B_{12}$ were independently associated with plasma tHcy levels. Although homocysteine level was independently influenced by both genetic (MTHFR) and environmental (folate and vitamin $\mathrm{B}_{12}$ ) factors, the partial $\mathbf{R}^{2}$ implied that the effects of folate and vitamin $\mathrm{B}_{12}$ on the tHcy level were larger than that of MTHFR gene. Furthermore, there was a significant gene-environmental interaction between MTHFR gene and serum folate. Therefore, future studies on the relationship between MTHFR gene and tHcy should be necessarily done considering such environmental factors.

Since the measurement of homocysteine is currently expensive, a mass screening for mild hyperhomocysteinemia may be impracticable. However, it would be a valuable advice for any people to take foods rich in folate (e.g., green soybeans, leafy and dark green vegetables, citrus fruits, citrus juice, and legumes) and vitamin $B_{12}$ (e.g., seaweed, shell-fish, fin-fish, and poultry) ${ }^{52,53,54)}$, and to quit smoking.

\section{ACKNOWLEDGMENTS}

This study was supported by the following grants: Grant-inAid for General Scientific Research (12470094) from Ministry of Education, Culture, Sports, Science and Technology of Japan; National Cardiovascular Center Grant-in-Aid; Japan Heart Foundation Research Grants. We also appreciate to thank to the staffs, many other collaborators, and volunteers in Shiso County, Hyogo Prefecture, Japan, as well as our colleagues.

\section{REFERENCES}

1. McCully KS. Homocysteine and vascular disease. Nat Med, 1996; 2: 386-389.

2. Welch GN, Loscalzo J. Homocysteine and atherothrombosis. N Engl J Med, 1998; 338: 1042-1050.

3. Fowkes FG, Lee AJ, Hau CM et al. Methylene tetrahydrofolate reductase (MTHFR) and nitric oxide synthase (ecNOS) genes and risks of peripheral arterial disease and coronary heart disease: Edinburgh Artery Study. Atherosclerosis, 2000; 150: 179-185.

4. Mudd SH, Uhlendorf BW, Freeman JM et al. Homocystinuria associated with decreased methylenetetrahydrofolate reductase activity. Biochem Biophys Res Commun, 1972; 46: 905-912.

5. Selhub J. Homocysteine Metabolism. Annu Rev Nutr, 1999; 19: 217-246.

6. Iwai N, Yoshiike N, Saitoh S et al. Leisure-time physical activity and related lifestyle characteristics among middle-aged Japanese. Japan Lifestyle Monitoring Study Group. J Epidemiol, 2000; 10: 226-233.

7. Jacques PF, Bostom AG, Williams RR et al. Relation between folate status, a common mutation in methylenetetrahydrofolate reductase, and plasma homocysteine concentrations. Circulation, 1996; 93: 7-9.

8. Nakai K, Fusazaki T, Suzuki T et al. Genetic polymorphism of 5,10-methylenetetrahydrofolate increases risk of myocardial infarction and is correlated to elevated levels of homocysteine in the Japanese general population. Coron Artery Dis, 2000; 11: 47-51.

9. Jee SH, Beaty TH, Suh I, Yoon Y, Appel LJ. The methylenetetrahydrofolate reductase gene is associated with increased cardiovascular risk in Japan, but not in other populations. Atherosclerosis, 2000; 153: 161-168.

10. Morita $\mathbf{H}$, Taguchi $\mathbf{J}$, Kurihara $\mathrm{H}$ et al. Genetic polymorphism of 5,10-methylenetetrahydrofolate reductase (MTHFR) as a risk factor for coronary artery disease. Circulation, 1997; 95: 2032-2036.

11. Ou T, Yamakawa-Kobayashi K, Arinami T et al. Methylenetetrahydrofolate reductase and apolipoprotein E polymorphisms are independent risk factors for coronary heart disease in Japanese: a case-control study. 
Atherosclerosis, 1998; 137: 23-28.

12. Ainsworth BE, Haskell WL, Leon AS et al. Compendium of physical activities: classification of energy costs of human physical activities. Med Sci Sports Exerc, 1993; 25: 71-80.

13. Jacques PF, Sulsky SI, Sadowski JA et al. Comparison of micronutrient intake measured by a dietary questionnaire and biochemical indicators of micronutrient status. Am J Clin Nutr, 1993; 57: 182-189.

14. Araki A, Sako Y. Determination of free and total homocysteine in human plasma by high-performance liquid chromatography with fluorescence detection. J Chromatogr, 1987; 422: 43-52.

15. Goyette P, Sumner JS, Milos R et al. Human methylenetetrahydrofolate reductase: isolation of cDNA, mapping and mutation identification. Nat Genet, 1994; 7 : 195-200.

16. Goyette P, Frosst P, Rosenblatt DS et al. Seven novel mutations in the methylenetetrahydrofolate reductase gene and genotype/peonotype correlations in severe methylenetetrahydrofolate reductase deficiency. Am J Hum Genet, 1995; 56: 1052-1059.

17. Frosst $P$, Blom $H J$, Milos $R$ et al. A candidate genetic risk factor for vascular disease: a common mutation in methylenetetrahydrofolate reductase. Nat Genet, 1995; 10: 111-113.

18. Boushey CJ, Beresford SA, Omenn GS, Motulsky AG. A quantitative assessment of plasma homocysteine as a risk factor for vascular disease. Probable benefits of increasing folic acid intakes. JAMA, 1995; 274: 1049-1057.

19. Nygard O, Vollset SE, Refsum H, Brattstrom L, Ueland PM. Total homocysteine and cardiovascular disease. J Intern Med, 1999; 246: 425-454.

20. Kang SS, Wong PW, Malinow MR. Hyperhomocyst(e)inemia as a risk factor for occlusive vascular disease. Annu Rev Nutr, 1992; 12: 279-298.

21. Kluijtmans LA, van den Heuvel LP, Boers GH et al. Molecular genetic analysis in mild hyperhomocysteinemia: a common mutation in the methylenetetrahydrofolate reductase gene is a genetic risk factor for cardiovascular disease. Am J Hum Genet, 1996; 58: 35-41.

22. Gudnason V, Stansbie D, Scott J et al. C677T (thermolabile alanine, aline) polymorphism in methylenetetrahydrofolate reductase (MTHER): its frequency and impact on plasma homocysteine concentration in different European populations. EARS group. Atherosclerosis, 1998; 136: 347-354.

23. McKinley MC. Nutritional aspects and possible pathological mechanisms of hyperhomocysteinaemia: an independent risk factor for vascular disease. Proc Nutr Soc, 2000; 59: 221-237.

24. Ma J, Stampfer MJ, Hennekens $\mathrm{CH}$ et al. Methylenetetrahydrofolate reductase polymorphism, plas- ma folate, homocysteine, and risk of myocardial infarction in US Physicians. Circulation, 1996; 94: 2410-2416.

25. Wilcken DE, Wang XL, Sim AS, McCredie RM. Distribution in healthy and coronary populations of the methylenetetrahydrofolate reductase (MTHFR) C677T mutation. Arterioscler Thromb Vasc Biol, 1996; 16: 878882.

26. Schmitz C, Lindpaintner K, Verhoef P, Gaziano JM, Buring J. Genetic polymorphism of methylenetetrahydrofolate reductase and myocardial infarction. A case-control study. Circulation, 1996; 94: 1812-1814.

27. Kang SS, Wong PW, Norusis M. Homocysteinemia due to folate deficiency. Metabolism, 1987; 36: 458-462.

28. Kang SS, Wong PW, Zhou JM et al. Thermolabile methylenetetrahydrofolate reductase in patients with coronary artery disease. Metabolism, 1988; 37: 611-613.

29. Anderson JL, King GJ, Thomson MJ et al. A mutation in the methylenetetrahydrofolate reductase gene is not associated with increased risk for coronary artery disease or myocardial infarction. J Am Coll Cardiol, 1997; 30: 1206-1211.

30. Malinow MR, Nieto FJ, Kruger WD et al. The effects of folic acid supplementation on plasma total homocysteine are modulated by multivitamin use and methylenetetrahydrofolate reductase genotypes. Arterioscler Thromb Vasc Biol, 1997; 17: 1157-1162.

31. Saw SM, Yuan JM, Ong CN et al. Genetic, dietary, and other lifestyle determinants of plasma homocysteine concentrations in middle-aged and older Chinese men and women in Singapore. Am J Clin Nutr, 2001; 73: 232-239.

32. Christensen B, Frosst $P$, Lussier-Cacan $S$ et al; Correlation of a common mutation in the methylenetetrahydrofolate reductase gene with plasma homocysteine in patients with premature coronary artery disease. Arterioscler Thromb Vasc Biol, 1997; 17: 569-573.

33. Matthews RG. Methylenetetrahydrofolate reductase from pig liver. Methods Enzymol, 1986; 122: 372-381.

34. Israelsson B, Brattstrom LE, Hultberg BL. Homocysteine and myocardial infarction. Atherosclerosis, 1988; 71: 227-233.

35. Andersson A, Brattstrom L, Israelsson $B$ et al. Plasma homocysteine before and after methionine loading with regard to age, gender, and menopausal status. Eur J Clin Invest, 1992; 22: 79-87.

36. Selhub J, Jacques PF, Wilson PW, Rush D, Rosenberg IH. Vitamin status and intake as primary determinants of homocysteinemia in an elderlly population. JAMA, 1993; 270: 2693-2698.

37. Ueland PM, Refsum H, Stabler SP et al. Total homocysteine in plasma or serum: methods and clinical applications. Clin Chem, 1993; 39: 1764-1779.

38. Brattstrom L, Lindgren A, Israelsson B, Andersson A, Hultberg B. Homocysteine and cysteine: determinants of 
plasma levels in middle-aged and elderly subjects. J Intern Med, 1994; 236: 633-641.

39. Finkelstein JD. Methionine metabolism in mammals. J Nutr Biochem, 1990; 1: 228-237.

40. Brattstrom L, Israelsson B, Norrving B et al. Impaired homocysteine metabolism in early-onset cerebral and peripheral occulusive arterial disease. Effects of pyridoxine and folic acid treatment. Atherosclerosis, 1990; 81: 51-60.

41. Dalery K, Lussier-Cacan S, Selhub J et al. Homocysteine and coronary artery disease in French Canadian subjects: relation with vitamins $B_{12}, B_{6}$, pyridoxal phosphate, and folate. Am J Cardiol, 1995; 75: 1107-1111.

42. Riggs KM, Spiro A 3rd, Tucker K, Rush D. Relations of vitamin B-12, vitamin B-6, folate, and homocysteine to cognitive performance in the Normative Aging Study. Am J Clin Nutr, 1996; 63: 306-314.

43. Ubbink JB, Delport R, Vermaak WJ. Plasma homocysteine concentrations in a population with a low coronary heart disease prevalence. J Nutr, 1996; 126(4 Suppl): 1254S-1257S.

44. Dierkes J, Kroesen M, Pietrzik K. Folic acid and Vitamin $B_{6}$ supplementation and plasma homocysteine concentrations in healthy young women. Int $\mathbf{J}$ Vitam Nutr Res, 1998; 68: 98-103.

45. Stampfer MJ, Malinow MR, Willett WC et al. A prospective study of plasma homocyst(e)ine and risk of myocardial infarction in US physicians. JAMA, 1992; 268: 877 881.

46. Brattstrom L, Lindgren A, Israelsson B et al. Hyperhomocysteinaemia in stroke: prevalence, cause, and relationships to type of stroke and stroke risk factors. Eur J Clin Invest, 1992; 22: 214-221.
47. Nygard O, Refsum H, Ueland PM, Vollset SE. Major lifestyle determinants of plasma total homocysteine distribution: the Hordaland Homocysteine Study. Am J Clin Nutr, 1998; 67: 263-270.

48. Nygard O, Vollset SE, Refsum H et al. Total plasma homocysteine and cardiovascular risk profile. The Hordaland Homocysteine Study. JAMA, 1995; 274: 1526-1533.

49. Piyathilake CJ, Macaluso M, Hine RJ, Richards EW, Krumdieck CL. Local and systemic effects of cigarette smoking on folate and vitamin B-12. Am J Clin Nutr, 1994; 60: 559-566.

50. Jacques PF, Bostom AG, Wilson PW et al. Determinants of plasma total homocysteine concentration in the Framingham Offspring cohort. Am J Clin Nutr, 2001; 73: 613-621

51. van der Gaag MS, Ubbink JB, Sillanaukee P, Nikkari S, Hendriks HF. Effect of consumption of red wine, spirits, and beer on serum homocysteine. Lancet, 2000; 355: 1522.

52. Food and Nutrition Board, Institute of Medicine. Dietary reference intakes for thiamin, riboflavin, niacin, vitamin $\mathrm{B}_{6}$, folate, vitamin $\mathrm{B}_{12}$, pantothenic acid, biotin, and choline. National Acadamy Press, 1999: 1-592.

53. Malinow MR, Bostom AG, Krauss RM. Homocyst(e)ine, diet, and cardiovascular diseases: a statement for healthcare professionals from the Nutrition Committee, American Heart Association. Circulation, 1999; 99: 178182.

54. The Resources Council, Science, and Technology Agency. Standard tables of food composition in Japan. 5 th rev ed. Printing Office of Ministry of Finance, Tokyo, Japan, 2000: 1-464. (in Japanese) 